\title{
The "David's Jump" - On the first positive change in the treatment of gifted children
}

\author{
Hanna David* \\ Tel Aviv University, Tel Aviv 6997801, Israel \\ *E-mail address: hannadav@post.tau.ac.il
}

\begin{abstract}
In spite of the difficulty in predicting the time any treatment is to take, working with gifted children and their parents includes - in many cases - a substantial improvement in a comparatively short time in at least one aspect of the child's life. As this phenomenon has not been named in the psychological literature, it will be called: "David's Jump". This article presents 5 cases of such "jumps", all in children 5-8 years old, all happened within 8-10 weeks from the beginning of the treatment as reported by the parents or by the children themselves. The potential causes of the success reached are to be discussed; some of them might also be relevant to non-gifted children.
\end{abstract}

Keywords: "David's Jump"; gifted children; treatment of young children

\section{INTRODUCTION}

A treatment is a process. There are no "rules" or "laws" regarding its length, as each treatment is unique. Thus, even if the "mean time" of psychological treatments can be calculatedfor patients of the same age, patients sharing the same problem, disorder or diagnosis, or patients that can be compared by any other criterion, this finding is meaningless; the duration of a treatment has nothing to do with any statistics. And indeed, it is very common among psychologists to believe that substantial changes do not occur in a short time, and if they do it should be advised to refer to them as temporal improvements.

However, working with gifted children and their parents in the last 25 years has proven that in many cases there is a "jump" in the treatment, a significant improvement in at least one aspect of the child's life in a very short time: The "David's Jump". When it happens it is an indication that "something good is happening" both for the child and her or his parents. Usually until the "David's Jump" the therapeutic process seems to the parents of the child quite amorphous in spite of all the explanations; from the time it happens the process becomes more concrete. The improvement, even when minor, usually accelerates an advancement in more areas, including those who had not been described by the parents as acute, and certainly not those who had been the reason for starting the treatment. The results of an updated study done by a team of American researchers support my findings. The study was conducted among children treated in community clinics, and showed that substantial improvements from one therapeutic session to the next were a good predictor of a long term success of the treatment as perceived both by the psychologist 
and the parents (Dour et al., 2013; Aderka, 2014). However, it seems that the "David's Jump" in treatment has been, until now, non-existing issue in the scientific literature, and thus it not even have an accepted term describing it.

In my work with children and their parents I make sure not to encourage the parents to expect a "David's Jump" in a short time - or at all. However, when it does happen I feel not only satisfaction and pleasure, but even happiness. As long as I am concerned - this is a miracle happening in treatment. There are parents who report immediately after the "David's Jump" had happened; others do it only after I ask them, a few weeks after the beginning of the treatment, to share their thoughts and feelings about it. The "David's Jump" appears in variety of forms: it is not always directly connected to the problem that had been the cause for starting the treatment, but it always pleases the parents as it shows them that even if there is still a long way to go, there are good prospects the process will be successful. The "David's Jump" also proves that the initial connection between the child and me has been established and thus I can expect a successful treatment.

In this article I will present five vignettes of the "David's jump" at the beginning of the treatment. I will focus on the connection between the time duration until the jump occurred and several factors.

\section{2. "FULL TEXT"}

I hereby present five case studies all of gifted children aged 5-8 where a "David's Jump" had occurred. A 5-year old girl who "did not want to grow" and thus it was hard to make her fall asleep in her own bed; an 8-year old boy who had become submerged in existential problems, especially death and dying, as a result of a loss in his family; a 7-year old highly intelligent boy with ADHD who did not accept school's rules and limitations; a boy who suffered a great deal from boredom due to his being extremely gifted, and a child who aroused a high level of antagonism because of his assertiveness.

\section{1. "David's Jumps" in the treatment of gifted children: Examples}

\subsubsection{Shani: "I want to be a little girl forever"}

Shani's parents contacted me for the first time before she was 5. They wanted me to help them find an appropriate school for her, as they realized both her verbal and mathematical abilities where extremely high. At this stage I did not think Shani needed to be in treatment. After a month the parents came for a second counseling session. During this session it became clear that the parents needed advice in many more issues. In addition, I was informed that after an intensive investigation of all kindergartens and schools in their neighborhood the parents came to the conclusion that none of them was appropriate for the girl who started reading at age 3 and knew the difference between million and billion at age 5. Even at this point I was not sure that parents' instruction was not all what this family needed, but I changed my mind when the parents told me that their daughter did not agree to go to sleep in her own bed. Within a week I started meeting Shani on a regular bases.

During our first meeting Shani explained how good it was "to stay a little girl". I asked her to write down the reasons for it; she filled, with her large, almost-perfect handwriting a whole A4 
page. This included: "I get almost everything I want"; "I do not have to go to the kindergarten when I do not wish to"; "everybody says I am a little charming girl" and many more. When asking her to write down the advantages of being a big girl, what she might get or what she might do but was not able or not allowed to do yet she could not find even one single thing... I tried to help her by suggesting a few ideas, such as: "you will be able to ride a bike without training wheels", but her reaction was: "but when riding with training wheels I never fall". I tried once more: "you will be able to travel abroad on your own" and she immediately answered: "I do not want to travel anywhere on my own". I finally realized that at this stage Shani enjoyed being "a little girl", and if she decided that it was time to grow up she would do that in spite of her perceiving the many loses she would have as substantial. One of the first loses would be giving up sleeping in her parents' bed.

During the instructing meeting taking place in the next week I showed the parents the full and the empty lists, and explained that if they felt it was time for their daughter to grow up they needed, probably for the first time in their lives, to be rigid and consistent with her, as until then she had always been a "good girl" and all restrictions and limitations seemed to her logical and thus she accepted them without questioning. The parents promised to tell Shani that she had to go to sleep in her own bed starting on that day.

As the mother was not quite sure she would be able to stand her daughter's crying, and she also expected that Shai was to have difficulties in falling asleep, I told her I was to call her every morning at 7am and ask: "how did it go yesterday". The mother could not believe I made such a suggestion, but I was willing to bet that the difficulties would not take long so I was ready to commit myself to the assignment. And indeed - I called the mother every morning for a week, received a report about Shani's crying, about the mother feeling "as if my heart was broken", but also about the success: Shani fell asleep in her own bed every single day.

A week later Shani reported directly to me. She asked: "do you know I am REALLY big"? I realized that for the first time in her life she had a reason for being proud of her emotional growth. Both the happiness and the pride she felt for being able to overcome her fears had a special meaning because until then she had achieved highly in all cognitive areas without any effort. It took Shani just one month until she completely got rid of the habit of falling asleep in her parents' bed. It still happened that when waking up in the middle of the night - either because of a bad dream or because of a noise waking her - she ran to her parents' room, but they would always take her back to her room and sit at her side until she fell asleep again in her bed.

If you wonder whether Shani continued her treatment - the answer is "yes". The parents, being very satisfied of her huge advancement in such a short time developed an appetite for reaching further aims. First they wanted her to become friends with other girls her age. Then Shani started participating afternoon activities, some of which were mixed-aged and some aimed for older children. Shani started closing the gap between her cognitive and emotional abilities, a gap typical to gifted children (Landau, 1991). Her emotional growth was visible: she became nicer and more polite to everybody, and started materializing her great ability for empathy, which made her more loved both by members of her extended family and strangers, and thus socially popular. She started her progress towards life in which her giftedness was a huge advantage rather than a burden, a life where her emotional as well as her cognitive age were higher than her chronological one, and the gap between her emotional and her chronological age did not exist any longer. 


\subsubsection{Gil: Speaking about death and asking about it}

After Gils' uncle, who was in his 40ies, died in a car accident, 8-year old Gil started being obsessed with death. He asked many questions, such as about the possibility of life after death, or the probability of dying in a variety of accidents and illnesses. He was very curious about this subject, collected every piece of information and used the data he had acquired to ask more about everything that had to do with death. Needless to say that this made his parents quite frightened, and they felt unable to help their son while being absorbed in their own loss, and in constant need of energy because the mourning process was draining them.

As the home atmosphere was, to say the least, far from cheerful, and as Gil was busy thinking about this frightening subject, the parents of his friends stopped inviting him over to their houses, while his own parents had no energy to entertain other parents or even host other children in their sad, mourning home. As a result Gil's loneliness increased, and an immediate action was needed in order to change this situation.

During my first meeting with Gil I realized he was not interesting in any kinds of games, but rather needed to speak with me. I found that in the past Gil's parents had been his main source of emotional support and made themselves available to him for a few hours every day. However, since the death of the mother's brother, who had also been a close friend of Gil's father, they had no energy for conversations with their son. Since our first meeting Gil was always "ready" for speaking - with a handful of subjects he had prepared ahead of time, new questions that he had as well as old ones: about subjects we had started discussing and he needed to get deeper into. The meeting started always with questions such as: "Do you believe in life after death?" or "in your opinion, is it possible that in my lifetime corpses would be frozen and defrost after healing or repairing?" I made my best to answer him as accurately as I could, but tried - if only possible -to start discussing a new subject. For example: when asked about life after death I started my answer by explaining that this term had different meanings in many ancient cultures, I focused on the description of heaven in Judaism and in Ezekiel's Vision of the Dry Bones, the concept of life after death in Christianity and Islam as well as in the Druze's contemporary belief in Reincarnation. We moved on to the different religions believing in Resurrection, about life in different forms and shapes from the ancient Greeks until contemporary Buddhism. At this stage I already realized that Gil was able to shift his personal mourning to more general subjects and questions, while each passing week he increased his knowledge about life after death.

During these weeks Gil gradually started other activities. He became a part of a Karate group practicing twice a week, and what was even more important for his parents - he invited two new friends he met in this group to his home, and also visited a few friends from school. During the meetings with me he complained time and again that his friends were not interested in the subjects he found most intriguing, but accepted the fact that "when one has many friends, it is possible to do many different things which each of them". In spite of his young age Gil understood that when spending time with friends he had to do things that were interesting for them. As his social interactions became more frequent he had lesser time left for thoughts about death.

From time to time Gil still felt angry because of the death that had such a substantial influence on his entire family, but he started directing the ager to statistical questions, such as: "what is the probability that a boy my age will lose an uncle?", or "what is the death rate of men belonging to my uncle's age group?" There were also more existential questions, such as "who is 
to blame for my uncle's death? Was it possible to prevent his death?" When such question aroused during our meetings we spoke about them; but I also taught Gil a few techniques for "driving the thoughts out" when he was feeling that "these thought overcome me and make me sad". For example: I asked Gil's parents to buy him a punch-bag and hang it in his room, and told Gil he should punch it, go for a long bike ride with the friend living in the next building, or watch national geography programs that he loved when feeling angry, sad or both. Gil taught himself to choose one of these optional activities whenever he felt he needed to, and his parents encouraged him to do that. This also taught him an important lesson in self-regulation.

Five weeks later it was obvious that the "David's Jump" happened. Even though death was discussed with me practically in all meetings, it was no longer overtaking Gil's life, and in a few weeks more it became just one of the many subjects Gil showed interested in.

\subsubsection{Cliff: Angry scenes in the way to school}

7-year old Cliff was a very intelligent ADHD child. According to his parents, every morning they had to face "scenes that make our life miserable" on the way to school. He just did not want to go to school and thus they had, quite often, to carry him to the car while he was shouting and kicking, push him into it, and pull him out at the school's gate. Cliff was one of the $15-25 \%$ of ADHD children who cannot take Ritalin as they either respond to it negatively or are indifferent to it (Grizenko et al., 2006). As a result Cliff suffered a great deal in school. He was unable "to sit quietly" as required, and he was bored most of the time, as are most gifted children in the regular classroom (David, 2009a, 2009b).

Cliff had informed his parents, right from the first school day in grade 2, that he "did not love the teacher". He told me in our first meeting that "there is a terrible noise in the classroom", that "every time I move the teacher becomes angry", and "even when I try my best to be quite, and succeed to do that during a whole class, I never get any praises, but when I stretch my legs just once - I get yelled at".

The parents told me that they were tired from school meeting with the teachers, the counselor, the headmistress and the psychologist, that they saw no point in hearing the teacher time and again saying "I cannot teach like that", and that they started feeling a pressure to move their son to "a small class", which is a code for a special education class. Because of the "Integration law (Integration of children with special needs in in elementary school, 2002), which allowed parents of disabled and retarded children to learn in regular schools, the vast majority of children who do learn in non-integrative constellations are severely impaired, many have a moderately or even profoundly intellectual disabilities, and thus cannot make a suitable peer-group for a gifted boy with a learning disability.

In this case the "David's Jump" happened after the parents changed their attitude towards school. Instead of explaining their son that "you should learn in school" and "you must obey orders" they just told him the truth: "indeed, school is boring", and at that stage there was a possibility that he was not going to acquire any new knowledge there, but as good citizens they must also obey the law of compulsory education, and make sure he was attending school. Furthermore, as the parents decided they did not want to listen to talks about the special education class they refused to come to school for any more meetings.

In addition, in spite of Cliff's young age his parents made use of his high cognitive abilities and talked with him about the socialization process that happens only in the company of other children. He was ok with the explanation and soon after told me that "I attend school only for the 
recess time". This conclusion made life much easier for him, and it was possible to start dealing with all other problems that bothered him, resulting from the combination between his giftedness and ADHD.

During our meetings I told him some simple techniques for early identification of urges such as "I need to stand up", "I have to leave the classroom" or "I can't go on raising my finger when the teacher speaks without ever being noticed, so I'll burst into her speaking". I made it clear, time and again, that he always had a choice. For example: he could stand up and walk around in the classroom, but when he did that he had no reason to complain for being punished. He could also stand up and leave the classroom - an option he opted for twice a day after his parents talked about it with his teacher and got permission to do that. When he chose the option "to overcome the urge" he got "5 points"; when he was entitled to 100 points he was eligible to buy, accompanied by one of his parents, books, games or software for the amount of 100 Shekel. ${ }^{1}$ At this stage the aims of the treatment seemed reachable; reaching each of them counted and was praised, and it looked as if Cliff got more satisfaction when his "overcoming" was mentioned than when he stopped getting punished.

Two months after the beginning of the treatment Cliff internalized that going to school was mandatory and "the morning terror" disappeared.

\subsubsection{Ron: Resistance to school and to the "yelling teacher"}

7-year old Ron came to me after his parents had given up school. He loved his friends there - even though he did not meet them in the afternoons - but regarding classes and all teachers, especially his main teacher, he was unambiguous: "she is boring", "she is stupid", "she is not fair", "she would never listen" and especially "she is shouting and yelling".

As is the case for many gifted children, Ron suffered from overexcitability in a few areas (Dabrowski \& Piechowski, 1977; David, 2009a; Piechowski, 2014). He overcame his tactile over-sensitivity by paying special attention to the way he was dressed: no stiches in the internal part of any garment, ripping off the label before putting any new article of clothing on, as well as washing it before wearing it for the first time. But Ron's problem because of his hyper-sensitivity to noise could not be completely solved. Both his parents and I told him that "sometimes the only solution is just leaving the noisy place". In addition, I asked him: "have you tried to shut yourself out from the voices when they sound like cacophony?" The new understanding, that in many cases, when suffering seems over-whelming, there is a possibility "not to be there" prevented Ron from bursting out in class when the noise was unbearable for him. In such cases sometimes he left the classroom, pretending to need the toilets urgently, and stay away from the noises until he felt he could face them again or until he thought the teacher had calmed the students down. During recess time Ron preferred not to join noisy groups, found quite places in the schoolyard or stayed in the classroom in order to "accumulate a few moments of silence".

Four weeks after the beginning of the treatment Ron's parents informed me about the "David's Jump". According to them, the main reason for that was that "Ron has interesting things to do". Of course, I agreed with them. Ron started learning math with a mathematician who was holding a $\mathrm{PhD}$, re-joined his chess club, and kept on swimming regularly in his highprestige group. All these interesting, quite activities helped him go through the less-enjoying and noisier activities during classes. He stopped correcting the teacher's mistakes, stopped arguing with her and with his peers, and even started doing homework - an initiation he explained as "it is better not to give the teacher any reason to come at you".

\footnotetext{
${ }^{1}$ About $25 \$$ or $20 \mathrm{EU}$.
} 


\subsubsection{Aron: Stubborn and "always right"}

6-year old Aron had suffered from a variety of problems, but it would be more accurate to say that his parents suffered more. Aron was stubborn, argumentative, with a strong tendency to be always right - in school and at home. His parents did not know how to deal with the situation and came to me almost in despair: they were tired from arguments, did not wish to jeopardize their relationship with him so they stopped punishing him, but realized that there was no change in his behavior after any conversations or explanations.

At this stage I asked the parents to make a least of all things that bothered them or made them angry regarding their son's behavior. Then they divided the list into two: one contained the things that were crucial to them; the other - those things they "could live with". They had differences regarding many items, so before showing both lists to me they had a "date" where they decided about each item whether it was important enough to remain in the "crucial" list or not. Afterwards they started the "this is what you must do" method consistently, namely, using 5or-less-word sentences when asking their son to do anything. As they never raised their voices but repeated their demand time and again, without any explanations, Aron was denied the pleasure of arguing with them. This along with the fact that the demands became much lesser than before made Aron obey them. For example: while in the past many discussions were about wearing short or long pants - these discussions did not exist any longer. If in the past there were rules regarding what was to be eaten first (for example: "fruits are to be eaten after the main dish") - they vanished as well. As Aron had no food deficiencies both parents agreed that "no energy should be spent on this issue".

It took only two weeks until the "David Jump" occurred at home, namely, the endless arguments decreased substantially. Unfortunately, in spite of the huge efforts of the parents to make school adopt this successful approach neither the teacher nor the headmistress would listen. The discussions about each demand Aron refused to obey, as well as the endless explanations of the teacher kept on going there. But the parents told the teacher that if she insisted to stick to her old, inefficient tactic instead of changing it to strict directions - they would not "play her game". The result of this declaration was that the teacher decreased her contacts with the parents, and they were not invited to school as often as before. Aron's suffering in school did not disappear, but the safe place, his home, helped him go through the long hours in school in a relatively peace.

\subsection{Factors influencing the first "jump" in the treatment of children}

In spite of the fact that each child is unique, no treatment is like any other one, and it is pointless to try drawing conclusions from one treatment - successful or not - to another, it is possible to identify a few factors that influence the time duration until the "David's Jump" happens in the treatment. This time duration is influenced by the nature of the problem as well as its intensity, the cooperation between the parents and the psychologist, the connection between the child and the psychologist, and the child's verbal level. There is also importance to the history of previous treatments, as unsuccessful interventions cause, almost always, a serious problem in earning the child's trust, at least during the first stages.

My experience has shown that the most important factor influencing the time until the "David's Jump" is the child's age. In almost all cases I have encountered, when the child's age was lower at the beginning of the treatment the time needed until the first substantial change was 
shorter. All the cases I have presented were of children aged 5-8, and in all of them the young age played a role in the fast improvement. The most rapid change was in Shani's case, who was the youngest in this group; it should, however, be mentioned that the fast improvement was not only due to Shani's very young age. Gil's case was an exception, as dealing with death was not characteristic for his age (David, 2014a), and it is uncertain whether the problem had occurred at all had Gil been younger by a year or two when losing his uncle.

In addition to the child's age, the cooperation with the parents is of great importance. We cannot ignore the unpromising statistics regarding success of psychological treatment in general and treatment of children in particular (David, 2014b). It is important to remember that unlike as with an adult, when the patient in treatment is a child, the decision of terminating the treatment might be the parents', sometimes against the therapist advice and in many cases - against the child's will, even when it might damage the patient's well-being (Bar-Sadeh, 2004; Lanyado, 1999; Howes, 2008; Penn, 1990). My experience has shown that the main reason for a premature termination of children's therapy is the parents' resistance. Even when the therapy is not terminated because of the parents' resistance, it is very hard to make an advancement in the therapy without full cooperation of the parents, especially an accelerated advanced one. In order to achieve such cooperation the parents must know they can rely on the therapist; that she is "somewhere there" for them as well, not just for their child.

One of the simple techniques I use for transmitting this message, about the importance of cooperation with the parents, is saying directly: "the child meets me once a week for 50 minutes. You spend with him $24 \times 7$ hours minus 50 minutes every week. Thus, without your help and support we will not succeed". Usually this is well understood, and when there is a success, especially when the parents notice the improvement within a short time from the beginning of the treatment, I say: "it is vanity to think this had happened because of me or thanks to me. YOU made it possible!"

In all the cases I have presented, there was full cooperation of the parents, even when at the beginning each of them had a different opinion. For example, in the treatment of 7-year old Cliff, who actively resisted going to school, both parents had to take part, at least in the first days, of the comparatively-aggressive action. While Cliff's father immediately accepted the rationale behind the treatment, without any questioning, it was much harder for the mother. She rightly said that she was the person in charge of making Cliff arrive at school on time at least 4 mornings a week, and explained her husband's rapid acceptance of my suggestion by claiming: "it is easy for him to agree. He has to deal with it on a regular basis only on Fridays, while I am in charge at least 4 mornings a week. In addition, when there is a message from school about Cliff's behavior - it is addressed to me". I suggested that she filtered all calls from school, and thus they would not have a choice but call her husband. Sharing the roles with her husband made it easier for the mother, she accepted my suggestion and the process was successful when both parents took part in it.

The type of the problem is, obviously, important as well. For example, when a child with ODD starts treatment, or when an adolescent has a behavioral disorder, it is hard to expect a quick improvement. Nevertheless, even if such cases it is recommended to hope that if the "David's Jump" will not occur in a few weeks - it will in several months.

In light of that, in the case of 7-year old Ron I felt that the improvement reported by the parents was not a gift for them, but for me too, as I did not expect it would happen in 4 weeks. This case was an exception, where in spite of the severity of the problem, the very young age of the patient, the treatment that started immediately after the disorder was diagnosed, the maximal 
cooperation of the parents and maybe a very good interaction with me - all helped to the fast improvement of the situation.

The interaction between the therapist and the child has a substantial importance of the "David's Jump". The interaction between the therapist and the child can be divided to a few categories, when at one pole stands the resisting child, who needs to be bribed by the parents or even forced to attend the therapeutic meetings. I am not familiar with such cases, as I have never continue treating child who did not ask to see me again after our first meeting. Before every first meeting, even with a 5-year old, I feel as I did before the audition for directing a TV program I failed in (because my face did not have "TV quality") 40 years ago. This is something I tell the parents in the 90-minute counseling meeting with them - a meeting that in some cases is also the intake (David, 2010). This has to do with the fact that gifted children, with whom I work, are in general very sensitive. Thus, my own experience prevents me from drawing any conclusions about treatments when the connection between the child and the therapist is not very good. As much as I am concerned, without a good connection there is no treatment, and without treatment it is obvious that there is no "David's Jump". No wonder in the cases I have presented the connection of the children and their parents with me contribute to the success of the treatment.

The last factor in this list is the verbal ability of the child. I believe this factor is crucial in treating all children, but the high level of verbal abilities common to gifted children is of a great advantage. There is a tight connection between one's verbal level and giftedness, as even if the child is not "verbally gifted" (Assouline \& Lupkowski-Shoplik, 2012; Jen et al., 2014; Sanders et al., 1995), having high verbal abilities is a characteristic of giftedness. During the last two decades I have realized that even when the child is still in kindergarten, and the problem he has is considered complicated, the conversations we have are not typical to children his age but to children two, three or even more years older. Thus, it does not matter if the child chooses to do a creative activity or mathematical riddles in our meetings. ALL activities are accompanied by conversations. The gifted children I meet are not just "ready" to talk; almost always they are eager to. The materializing of the "passion to talk" is of great help to the "David's Jjump" - for the substantial improvement in a comparatively short time.

Aron, who was "way too much verbal", demonstrated the importance of the verbal component. Being argumentative, and the endless discussions as a result of it - were a central cause of tension and quarrels both at home and in school. In treatment I made use of Aron's high verbal ability, and taught his parents how to benefit from it as well. Without utterances such as "now you must listen" or "it is better if you learn" they taught him that as their son he must obey to anything said in imperative. A child who has a large vocabulary of words and expressions and is familiar with a variety of forms sentences can be said learns very quickly any new speech rule. Such a child will not be impressed by abundance of words but rather by the exact use of the "right" sentence in the right time. It is, though, a pity that in school nobody agreed to recruit Aron's high verbal abilities to make him understand it would be beneficial to accept the verbally expressed rules.

\section{CONCLUSION}

This article described five vignettes of 5-8-year old gifted children who experiences the "David's jump": a substantial improvement within two months from the beginning of the treatment, and in some cases - in just four. Each of these children was referred to me because of 
a different problem, but in all cases the child's giftedness had a close connection to the problem. In all cases the cooperating with the parents helped the child and enabled the "David's Jump", which, in its turn, gave hope for further improvements both for the child and his parents and for me. Unfortunately not even in one case the education system was willing to cooperate with the process.

Of the five factors I mentioned as responsible for the "David's Jump" four are probably important to non-gifted children as well: the child's age; the cooperation between the psychologist and the parents; the type of the problem, and the relationship between the child and the psychologist. The fifth - the child's urge to talk, as well as the high verbal abilities, might not be crucial for regular children. As I am experienced in working with gifted, talented and creative children, and my conclusions rely only on my own experience, and not on literature - which practically does not exist - in this subject, these conclusions should not be perceived as having a general validity. They are but a first step in introducing the "David's jump" concept, and a call for further investing it, in the hope that more therapists will contribute from their knowledge and experience to it.

\section{ACKNOWLEDGEMENT}

Thanks to the parents of the children who allowed me to publish the stories of their children. However, all details have been changed in order to prevent any possibility of recognizing the children or their families.

\section{BIOGRAPHY}

Hanna David(née: Ehrenstein), PhD was born in Jaffa in 1952 to a father immigrating to Israel from Vienna in 1938, and Hungarian mother, a survivor of Auschwitz. Dr. David's interest in giftedness started when she was 11, with the birth of her gifted brother. While still in high school she became an expert of accelerated teaching for UltraOrthodox boys whose parents wanted them to get "secular" education in addition to the religious one they received in school.

Teaching and counselling the gifted became Hanna's recognized expertise in 1995. In the last 20 years, Dr. David has become a popular counsellor for gifted students, with or without disabilities; a known expert of gifted education in Israel and abroad, an often invited lecturer in national and international conferences and meetings; an expert evaluator for the European commission, and a prolific writer of 14 books and over 150 articles.

\section{References}

[1] Dour, H.J., Chorpita, B.F., Lee, S., \& Weisz, J.R. (2013). Sudden gains as a long-term predictor of treatment improvement among children in community mental health organizations. Behaviour Research and Therapy, 51(9), 564-572.

[2] Aderka, I.M. (2014). Commentary. Evidence Based Mental Health, 17(1). Retrieved on 9 July 2014 from: http://ebmh.bmj.com/content/17/1/6.full

[3] Landau, E. (1991). The courage to be gifted. Hawker Brownlow Education, Moorabbin Victoria: Australia 
[4] Grizenko, N., Bhat, M., Schwartz, G., Ter-Stepanian, M., \& Joober, R. (2006). Efficacy of methylphenidate in children with attention-deficit hyperactivity disorder and learning disabilities: a randomized crossover trial. Journal of Psychiatry \& Neuroscience, 31(1), 46-51.

[5] David, H. (2009a). Five Gifted Boys in one Classroom: A Case-Study. In H. David, \& E. Wu, Understanding Giftedness: A Chinese-Israeli Casebook (pp. 24-36). Hong Kong: Pearson Education South Asia.

[6] David, H. (2009b). Giftedness and immigration: Case study of a gifted family emigrating from Russia to Israel. Australasian Journal of Gifted Education, 18(1), 37-47.

[7] Integration of children with special needs in in elementary school (2002) (Hebrew). Retrieved on 28 July 2014 from: http://www.kolzchut.org.il

[8] Dabrowski , K., \& Piechowski, M.M. (1977). Theory of levels of emotional development (Vols. 1 \& 2). Oceanside, NY: Dabor Science.

[9] Piechowski, M.M. (2014). 'Mellow out' they say. If you only could. Intensities and sensitivities of young and bright. Unionville, NY: Royal Fireworks Press.

[10] David, H. (2014a). Termination of treatment of gifted disabled students. Gifted Education Press, Fall 2014, 28(4), 11-20.

[11] David, H. (2014b). Suicide threats and suicide attempts among the gifted. Gifted Education Press, Spring 2015, 29(2).

[12] Bar-Sadeh, N. (2004). End of treatment. Issues in the psychotherapy of children. Retrieved on 29 July 2014 from: http://www.hebpsy.net/articles.asp?id=233

[13]Lanyado, M. (1999). Holding and Letting Go: Some Thoughts about the Process of Ending Therapy. Journal of Child Psychotherapy, 25(3), 357-378.

[14] Howes, R. (2008). Terminating Therapy. Part I: What, Why, How? Retrieved on 17 March 2014 from: http://www.psychologytoday.com/blog/in-therapy/200809/terminating-therapypart-i-what-why-howPart II: The Ideal Termination. What's the best reason to end therapy? Retrieved on 17 march 2014 from: http://www.psychologytoday.com/blog/intherapy/200810/terminating-therapy-part-ii-the-ideal-terminationPart III: The Not-QuiteIdeal Termination. Ending therapy on a sour note. Retrieved on 17 march 2014 from: http://www.psychologytoday.com/blog/in-therapy/200810/terminating-therapy-part-iii-thenot-quite-ideal-termination

[15] Penn, L.S. (1990). When the therapist must leave: Forced termination of psychodynamic therapy. Professional Psychology: Research and Practice, 21(5), 379-384.

[16] David, H. (2010). Gifted Case Studies: Keynote. In A. İşsman \& Z. Kaya (eds.), International Conference on New Horizons in Education: Proceedings book (pp. 7-23). Famagusta, Cyprus, $23^{\text {rd }}-25^{\text {th }}$ June 2010.

[17] Assouline,S.G. \& Lupkowski-Shoplik, A. (2012). The Talent Search Model of Gifted Identification. Journal of Psychoeducational Assessment,30(1), 45-59. 
[18] Jen,E., Chifen Tseng,C., \& Kuo, C.-C. (2014). Performance differences betweenverballytalented preschoolers and their regular counterparts in storytelling. GiftedEducation International,

[19] Sanders, C. E., Lubinski, D., \& Benbow, C. P. (1995). Does the Defining Issues Test measure psychological phenomena distinct from verbal ability? An examination of Lykken's query.Journal of Personality and Social Psychology, 69,498-504.

( Received 21 January 2015; accepted 29 January 2015 ) 